Journal of Patient-Centered coAdvocateAuroraHealth

Research and Reviews

Volume 5

Issue 1 - Health Disparities and Inequities: Part

Article 4 II

$1-30-2018$

\title{
Challenges of Refugee Health Care: Perspectives of Medical Interpreters, Case Managers, and Pharmacists
}

Fabiana Kotovicz

Anne Getzin

Thy Vo

Follow this and additional works at: https://aah.org/jpcrr

Part of the Family Medicine Commons, Health and Medical Administration Commons, Health Services Research Commons, International Public Health Commons, Medical Humanities Commons, Other Public Health Commons, and the Primary Care Commons

\section{Recommended Citation}

Kotovicz F, Getzin A, Vo T. Challenges of refugee health care: perspectives of medical interpreters, case managers, and pharmacists. J Patient Cent Res Rev. 2018;5:28-35. doi: 10.17294/2330-0698.1577

Published quarterly by Midwest-based health system Advocate Aurora Health and indexed in PubMed Central, the Journal of Patient-Centered Research and Reviews (JPCRR) is an open access, peer-reviewed medical journal focused on disseminating scholarly works devoted to improving patient-centered care practices, health outcomes, and the patient experience. 


\title{
Challenges of Refugee Health Care: Perspectives of Medical Interpreters, Case Managers, and Pharmacists
}

\author{
Fabiana Kotovicz, MD, ${ }^{1,2}$ Anne Getzin, MD, ${ }^{1,2}$ Thy Vo, MD ${ }^{2,3}$ \\ ${ }^{1}$ Aurora University of Wisconsin Medical Group, Aurora Health Care, Milwaukee, WI; ${ }^{2}$ Department of Family Medicine \\ and Community Health, University of Wisconsin School of Medicine and Public Health, Madison, WI; ${ }^{3}$ Department of \\ Psychiatry Residency Training, University of Pittsburgh, Pittsburgh, PA
}

Purpose $\quad$ Our objective was to identify perceived challenges in the provision of health care for refugees from the perspective of medical interpreters, case managers, and pharmacists working with refugee patients in Milwaukee, Wisconsin.

Methods Two 60-minute focus groups were performed exploring challenges in refugee health care using a literature-based semi-structured protocol. Focus groups were transcribed and de-identified prior to independent analysis by two of the investigators. Using a memoing-process qualitative approach, major concepts, cross-cutting themes, and subthemes were established and ultimately developed a narrative. The project protocol was approved as not human subject research by the local institutional review board.

Results $\quad$ Four overarching themes regarding health care for refugee patients were identified: 1) difficulty balancing the dynamic of autonomy versus support for refugees; 2) educational needs of refugee families outpacing available resources; 3) challenges for refugees developing trust; and 4) diversity of cultures, education levels, and experiences among refugee families. Language barriers in accessing health care services and insufficient time to meet educational needs of refugees were major challenges outside of the clinic visit setting. Poor health literacy and difficulties communicating health needs and building trust within the interactive triad of refugee, physician, and interpreter impacted clinic visits.

Conclusions Refugee patients and other participants in refugee care work to navigate a complicated path to equitable health care for a vulnerable population. Continued pursuit of strategies that increase time allocation, education, and support for all parties are needed as we seek to improve health outcomes for newly arrived refugee families. (J Patient Cent Res Rev. 2018;5:28-35.)

Keywords refugees; barriers; challenges; primary care; communication

$\mathrm{D}$ uring the past decade more than 600,000 refugees have resettled in the United States, with the largest groups fleeing wars and political conflicts in Burma (92,513), Iraq (74,477), Somalia (61,737), and Bhutan $(60,776) .{ }^{1}$ These refugees are racially, culturally, and linguistically diverse. In comparison to other immigrants, refugees

Correspondence: Fabiana Kotovicz, MD, Aurora St. Luke's Medical Center, 2801 W. Kinnickinnic River Parkway, \#250, Milwaukee, WI, 53215,

T: +1-414-385-4818, Email: fabiana.kotovicz@aurora.org are more likely to arrive with significant preexisting medical problems, with their health often affected by traumatic events, ${ }^{2,3}$ experiences of discrimination, and limited access to public health services. ${ }^{4-6}$

Primary care clinics are often the first access point to health care for refugees, ${ }^{7}$ and health care barriers for this population are well documented..$^{8-11}$ Communication and language barriers, acculturation challenges, divergent cultural beliefs about health, and difficulty establishing trust are a few of the noted obstacles. ${ }^{12,13}$ The impact of such obstacles is magnified in patients with chronic health conditions and disabilities ${ }^{14,15}$ as 
they have unique long-term needs within the complex and fragmented U.S. health care system. ${ }^{2}$

Primary care providers experience significant challenges in caring for refugees. Insufficient time to address refugees' needs is particularly difficult given that refugee populations are often unfamiliar with the concepts of prevention and long-term treatment of asymptomatic conditions and require greater amount of time for health education. Primary care providers also may have knowledge deficits regarding refugee experience and common diseases. Barriers to building rapport can impact provision of efficient and effective care due to patient reluctance to disclose important aspects of their health. ${ }^{6,7}$

Even with the assistance of medical interpreters, language barriers constitute one of the most important obstacles to providing quality health care. ${ }^{16,17}$ Lack of knowledge of the health care system and reduced ability to negotiate and advocate for themselves creates barriers to access services, comply with medical recommendations, and succeed within the social context, making resettlement more difficult. ${ }^{4,18,19}$

In the current literature there is limited exploration of the experiences of case managers, interpreters, and other key health care team members in regard to challenges faced in the efforts to access equitable health care for refugee populations. ${ }^{12}$ This study aims to identify perceptions of challenges in the provision of health care for refugees from the perspective of health care team members other than physicians: medical interpreters, case managers, and pharmacists.

\section{METHODS}

\section{Study Design}

Two focus groups were conducted to investigate perceptions regarding barriers to access and delivery of quality health care services to the refugee population in Milwaukee, Wisconsin. A qualitative study, utilizing in-depth focus group interviews with refugee resettlement case managers, interpreters, and pharmacists with experiences in refugee care was used to identify and interpret major themes and to develop authentic descriptions of the phenomena we studied. ${ }^{20,21}$ The project protocol was approved as not human subject research by the Aurora Health Care institutional review board.
Using typical case sampling, case managers and medical interpreters who work with refugee patients in Milwaukee were invited via email to participate in both focus groups exploring challenges in refugee health care. To gain a clinical perspective in the context of theoretical sampling, clinical pharmacists were invited to participate in the second focus group. A follow-up email was sent to nonrespondents. A total of 11 and 4 participants were present during the first and second focus group, respectively. The same set of questions was asked at both focus groups, which lasted 60 minutes each. Both focus groups were facilitated by the same co-investigator to maintain consistency, using a semi-structured interview protocol (Table 1). Anonymity was protected by using alias during the interviews and maintaining them throughout recording, transcription, and analysis.

\section{Analysis}

Two investigators, not present during the focus groups, independently reviewed the transcript line by line and developed individual memos that identified major concepts within the focus group using a qualitative analysis memoing process. ${ }^{22,23}$ The two investigators then convened on three different occasions and clustered memos from each interview; a third investigator mediated topic disagreement if needed. Analysis of these memo clusters yielded common cross-cutting themes and categories between interviews, with consensus and validation reached through discussion. Reviewers explored subthemes and relationships to larger categories to ultimately develop a narrative.

Using the aforementioned thematic analysis, barriers and challenges experienced during the resettlement process were classified as pertaining solely or concurrently to refugees, interpreters/case managers, and physicians from medical interpreters, case managers, and pharmacist's perspectives. They were further classified according to context as occurring outside or during the medical encounter (Figures 1 and 2).

\section{RESULTS}

The analysis demonstrated overarching themes that were revisited frequently by participants as they reflected on a multitude of challenges faced throughout the process of health care for refugee families during and outside of the clinic visit. These themes included difficulty in balancing the dynamic of autonomy versus 
Table 1. Focus Group Protocol

\begin{tabular}{|c|c|}
\hline $\begin{array}{l}\text { Topic 1: } \\
\text { Issues prior to medical } \\
\text { appointment with provider }\end{array}$ & $\begin{array}{l}\text { Please comment on problems or challenges you observe with the following: } \\
\text { - Refugees' perceptions of health care in United States } \\
\text { - Setting up appointment } \\
\text { - Transportation to hospital or clinic } \\
\text { - Communication with receptionist } \\
\text { - Understanding of purpose of appointment }\end{array}$ \\
\hline $\begin{array}{l}\text { Topic 2: } \\
\text { Issues with patient-provider } \\
\text { interactions }\end{array}$ & $\begin{array}{l}\text { Please comment on problems you observe with the following: } \\
\text { - Cultural understanding between patient and provider } \\
\text { - Comfort level between patient and provider } \\
\text { - Communication barriers } \\
\text { - Willingness of patient to disclose personal health information } \\
\text { - Problems with patients' understanding of own health condition }\end{array}$ \\
\hline $\begin{array}{l}\text { Topic 3: } \\
\text { Addressing barriers } \\
\text { to patient-provider } \\
\text { communication }\end{array}$ & $\begin{array}{l}\text { What can health care providers do to improve communication with patients? } \\
\text { What qualities in a health provider make patients more comfortable and open during a visit? } \\
\text { How can providers help patients understand their health condition and management? } \\
\text { Barriers to understanding condition/treatment } \\
\text { What makes it difficult for you as interpreters to translate medical information to refuges in } \\
\text { an understandable manner? }\end{array}$ \\
\hline $\begin{array}{l}\text { Topic 4: } \\
\text { Setting up and keeping } \\
\text { follow-up appointments }\end{array}$ & $\begin{array}{l}\text { Please comment on the following: } \\
\text { - Issues with patients setting up follow-up appointments } \\
\text { - Barriers in language, understanding of purpose of follow-up, navigation of health care } \\
\text { system, cultural perceptions, etc } \\
\text { - Issues with keeping scheduled appointments (transportation, cost, other barriers, etc) }\end{array}$ \\
\hline $\begin{array}{l}\text { Topic 5: } \\
\text { What can be done? }\end{array}$ & $\begin{array}{l}\text { In general, what do you think are the biggest challenge in providing refugee health care? } \\
\text { What can be done to address these challenges? } \\
\text { How can we make communicating easier for medical interpreters during patient-provider } \\
\text { interactions? }\end{array}$ \\
\hline
\end{tabular}

support for refugees navigating health care services; educational needs of refugee families outpacing available resources; challenges for refugees existing in development of trust throughout the resettlement process; and a striking diversity of cultures, education levels, and experiences for each refugee family (Table 2).

\section{Outside the Visit}

Accessing Health Care: Major challenges identified outside of the visit included difficulties accessing health care services due to language barriers. Often families were perceived to be dependent on interpreters or a family member who speaks English to schedule and arrange appointments. The complexity and fragmentation of the U.S. health care system was noted to complicate access for patients. Participants reflected that refugee families were confused by multiple specialists and locations for health care services, especially in the setting of limited transportation and language resources. One participant reflected, "It's hard to even get the sense that you have just one home base ... it's such a broken-up system. When I encounter the medical system, all I see is multiplied for the refugees."

Education: Participants identified a discrepancy between the high needs of refugee families and insufficient resources available for cultural orientation, education on basic aspects of health care services and prevention, and mental health screening. For example, participants repeatedly noted refugees had misperceptions regarding immunizations and green card requirements that conflicted with the actual standard immunization schedules: "My challenge with the refugees is they have in their head that they need to have all their vaccinations before they get their green card or they won't get it ... that if their bill is not paid, that's going to go against their green card. They get very anxious."

Participants reflected that there are existing curricula for refugee patient education on health care, insurance, and green cards, but they uniformly identified time and resources allotted as falling far short of the refugee families' needs. One participant stated, "When 

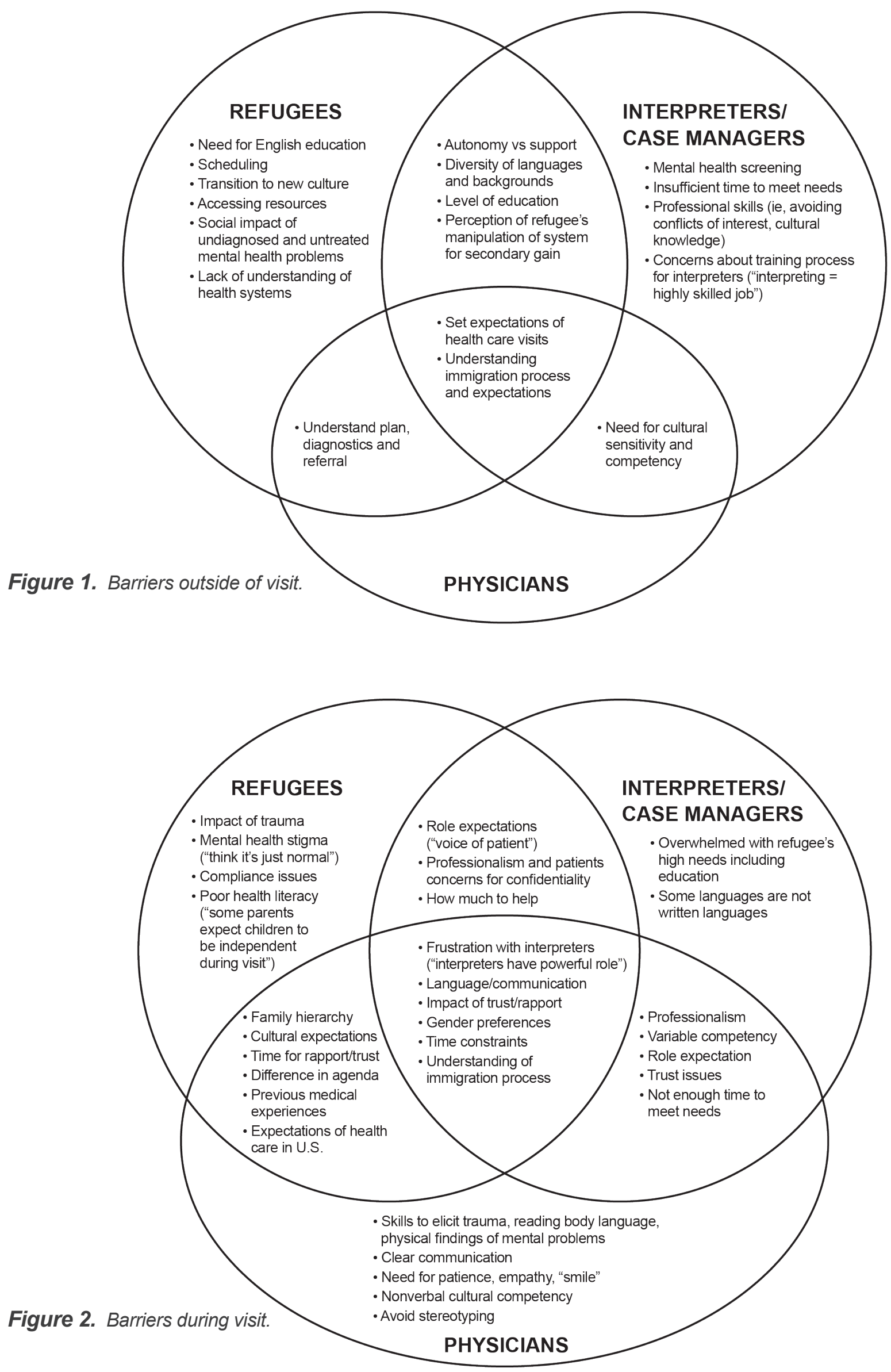


\begin{tabular}{|c|c|c|c|}
\hline ed for autonomy & rust & ducation/support needs & Diversity of each family \\
\hline $\begin{array}{l}\text { "For some of our clients, after } \\
\text { working with them for a while, } \\
\text { they get to know the interpreters. } \\
\text { Sometimes the interpreters } \\
\text { schedule the appointments, etc. } \\
\text { The clients then depend on others } \\
\text { to make their appointments. After } \\
\text { 2-3 years, if something happens } \\
\text { to them, and they stop with the } \\
\text { interpreters, they think, 'What did } \\
\text { I do to my life?' It's sometimes } \\
\text { harmful." } \\
\text { "They have to take initiative; } \\
\text { the agencies have to explain } \\
\text { they're no longer in the camps } \\
\text { or in Burma, they're in America. } \\
\text { They have to transition from their } \\
\text { mentality of living in the village } \\
\text { camps or Malaysia, where they } \\
\text { depend on someone else. They } \\
\text { have to learn how to build support } \\
\text { for themselves, not depend on } \\
\text { someone else. Someone has } \\
\text { to take the initiative so they can } \\
\text { uplift themselves and take care of } \\
\text { themselves." } \\
\text { "We can't spend } 40 \text { hours a week } \\
\text { with one client with high needs. } \\
\text { Ultimately, it's not going to happen. } \\
\text { The ability to advocate for oneself } \\
\text { needs to be learned so that as } \\
\text { we go about our busy needs and } \\
\text { someone falls through the cracks, } \\
\text { they can call and say they need } \\
\text { help. We'll have issues unless we } \\
\text { teach them to self-advocate." }\end{array}$ & $\begin{array}{l}\text { "I've had clients you } \\
\text { can ask one question } \\
\text { and they'll tell you } \\
\text { their whole life story, } \\
\text { and that's too much } \\
\text { information. There } \\
\text { are others you ask a } \\
\text { simple question and } \\
\text { you can tell they don't } \\
\text { want to answer, and } \\
\text { they're just giving you } \\
\text { the runaround, bringing } \\
\text { things up that have } \\
\text { nothing to do with that } \\
\text { question." } \\
\text { "I have a lot of refugees } \\
\text { who are very untrusting; } \\
\text { it makes it harder. They } \\
\text { don't trust anyone in the } \\
\text { resettlement company, } \\
\text { they think case } \\
\text { managers steal their } \\
\text { money or don't give } \\
\text { them enough house } \\
\text { supplies or furniture." } \\
\text { "The distrust travels on } \\
\text { to the appointments; } \\
\text { they don't trust anyone, } \\
\text { and they think everyone } \\
\text { is cheating them. The } \\
\text { distrust is everywhere. } \\
\text { I have a hard time } \\
\text { breaking the ice with } \\
\text { some of the patients } \\
\text { because of what they } \\
\text { went through. At the } \\
\text { doctor's office, they } \\
\text { don't trust anyone." }\end{array}$ & $\begin{array}{l}\text { "Most people understand the first } \\
\text { appointment. Most refugees don't } \\
\text { understand the purpose of the } \\
\text { next appointment. Sometimes } \\
\text { they are confused because before } \\
\text { coming they lived in camps, } \\
\text { and those camps don't have the } \\
\text { capability of preventing disease } \\
\text { and screening." } \\
\text { "Medical appointments can be } \\
\text { too much work and burdensome } \\
\text { when the refugees don't } \\
\text { understand the purpose of } \\
\text { medical follow-up appointments. } \\
\text { I think we need to give some } \\
\text { refugees training (in orientation } \\
\text { classes or something) to explain } \\
\text { how appointments work in the } \\
\text { U.S." } \\
\text { "When I have a whole lesson plan } \\
\text { and we only cover two sentences } \\
\text { in a 1-hour class, there's only } \\
\text { so much you can add to an } \\
\text { 8-week class. So even when } \\
\text { they completed that orientation, } \\
\text { they're not coming to you with the } \\
\text { understanding that is necessary } \\
\text { to function in a certain setting, } \\
\text { depending on the individual." } \\
\text { "I think they can benefit from } \\
\text { having a doula from the culture } \\
\text { who is well-versed in the medical } \\
\text { system. Because a lot of our } \\
\text { clients who are having a baby } \\
\text { for the first time, maybe as a first } \\
\text { pregnancy in the U.S., it's just } \\
\text { what they're used to." }\end{array}$ & $\begin{array}{l}\text { "From my experience, } \\
\text { when providers see } \\
\text { a female wearing a } \\
\text { scarf, they assume she } \\
\text { doesn't want any men. } \\
\text { That isn't necessarily } \\
\text { true, it depends on the } \\
\text { individual. Sometimes } \\
\text { if it's a health provider, } \\
\text { then it's okay. Some } \\
\text { Muslims don't wear any } \\
\text { scarves, and they don't } \\
\text { want male providers. } \\
\text { You can't just assume by } \\
\text { their appearance." } \\
\text { "They all have their own } \\
\text { opinion in how they } \\
\text { go about things and } \\
\text { how deep they are in } \\
\text { their religion. You can't } \\
\text { assume - she wears a } \\
\text { scarf, no men; no scarf, } \\
\text { it's okay. Always ask." } \\
\text { "It depends case by } \\
\text { case. Sometimes } \\
\text { females prefer female } \\
\text { providers. Some serious } \\
\text { cases, if they really need } \\
\text { something medical, they } \\
\text { rather go to the best } \\
\text { providers." }\end{array}$ \\
\hline
\end{tabular}

providers hear they're a refugee, they got to resettle, they have an 8-week cultural orientation - don't depend on that 8-week orientation. We can't even cover the basics, it takes so long."

\section{During the Visit}

Health Literacy: Poor health literacy was highlighted as having a high impact on adherence to medical recommendations by refugee patients. Many refugees were perceived to be missing basic health care concepts such as the need for individual appointments for each family member and refills for chronic disease medications despite being asymptomatic. Education around basic concepts prolongs visits, and participants reflected on the frustration that is experienced by all parties (provider, interpreter, patient) when in-person interpreters have to leave before the conclusion of the visit due to time limitations. Insufficient time scheduled for visits in the context of the high needs of this population was regarded as an important cause of delays on providers' and interpreters' schedules making it even more challenging to meet expected needs. 
Trust, Sensitive Health Issues: Refugee patient mistrust in the health care system was identified by several participants. Participants recalled multiple occasions of refugees asking about why so much blood is taken at screen examinations, asking "Are they selling the blood?" The distinct structure of medical visits in the U.S. also was mentioned as a source of misunderstanding within refugees who are often surprised with "too many" questions and the process of shared decision-making, making it even more challenging for providers to obtain clinically important information.

Mental health is one area that was seen as particularly challenging. Participants attributed this to a number of variables, including refugee and provider cultural differences and conceptualization of mental health. Refugees were noted to have difficulties in expressing mental health symptoms due to language barriers, and need for greater trust between the patient-providerinterpreter triad. For example, one participant reflected, “They don't want to say they're depressed, they don't think they're depressed, they think it's just normal. It's a big thing for them to disclose that, they're not doing it."

Communication and Expectations: Participants noted several opportunities for improvement in communication during medical visits as they identified a frequent disconnect between patient expectations and provider goals for the medical encounters. Multiple participants reinforced the need for clear explanation of the context for the visit and more education with use of teach-back methods and open-ended questions. One participant stated, "Context is everything. Don't just start with your own topic." Another reflected, "One of the first things you learn is not to ask yes or no questions because they always say yes. Ask openended questions, and they'll give you feedback."

\section{Dynamics in Communication (Doctor, Patient,} Family, Interpreter): The refugee patient-providerinterpreter interactive triad was explored in depth by participants. Physician concerns about accuracy of translation and lack of understanding of certain translation challenges for medical words without a direct, equivalent translation in the patient's language were cited as having an impact on the providerinterpreter dynamics. One participant: "It's very difficult to find words to translate in our language.
Some words we have to explain indirectly. Like MRI ... we have to explain it's a big machine that you go in and they take your picture." Another participant reflected on the challenging dynamic from high expectations by patients and providers directed at the interpreter: "It can be uncomfortable and challenging because on one hand the patient respects and puts a lot of trust on [interpreters] and the doctor expects a lot from [interpreters]. It's very hard to meet those demands when they feel disrespected on both sides. So building that trust and bouncing off everyone's ideas together with education is very valuable."

The presence of an in-person interpreter was identified as an effective strategy to decrease anxiety regarding quality of interpretation and communication for all parties involved. Family member presence during the appointment was perceived to improve patient comfort and facilitate communication, while family hierarchy also was noted to potentially compromise accuracy of history-taking and the overall patientprovider interaction. Physicians having more experience working with refugees and interpreters were noted to have a beneficial effect for communication involving all parties as well as trust building, and lack of experience with appropriate use of interpreters, particularly during specialty care visits, was identified as a concern. Participants mentioned that when effective communication does take place, refugees were noted to be more compliant than nonrefugee patients as a group.

\section{DISCUSSION}

Consistent with many studies in the literature, our study identified key factors, including the complexity and fragmentation of the U.S. health care system, language barriers, health literacy, and cultural differences, that set the context for challenges complicating the provision of health care for refugees. ${ }^{72,13}$ These challenges create a demand for longer visit times, better resource allocation, and a more standardized and culturally informed approach to support refugee patients, ${ }^{24}$ which was seen as currently insufficient by our study participants. Some comments made by focus group participants reflected frustration with not only the system, but impatience with refugees' high degree of needs and acculturation process, which is concerning in its potential to add to and exacerbate existing complex barriers during an already difficult cultural transition in the resettlement period. 
During the course of the clinic visit, greater time is needed for improving communication and education, which is complex both due to language barriers as well as cultural differences. Delivering quality care and support for refugee patients, especially around sensitive health care needs including mental health, ${ }^{25}$ requires the development of trust and rapport between the patient and provider. Although a growing literature underscores the high-risk factors and complexity of mental health disorders among refugees, health care providers are generally not equipped in providing appropriate mental health screening within this population, making it very challenging to identify and consequently treat. ${ }^{24,26}$ Clinicians frequently have very limited knowledge of a refugee's trauma history and mental health background, and no guidance on how to approach these patients. ${ }^{27}$ Thus, establishing trust in these contexts requires time, quality interpretation, and provider education regarding their patients' past experiences and cultural background ${ }^{12,28}$ and, as highlighted by Kaplan et al, is prerequisite for meeting needs of disadvantaged populations.

Finding the balance between supporting the needs of refugee patients during resettlement without jeopardizing autonomy and creating an environment conducive to dependency was a key theme mentioned frequently by participants. Dubus' work on experiences of medical interpreters demonstrated that interpreters often felt stress and strain as their work would extend into roles of advocacy and support beyond strictly medical interpreting. ${ }^{28}$ Indeed, caseworkers and interpreters in our study readily identified a wide range of challenges for refugees in accessing health care before the visit itself, including outside clinic barriers such as scheduling appointments, locating clinics, knowledge of basic health care concepts, and understanding insurance. In our study, assistance with these processes has been performed by interpreters as well as caseworkers from resettlement agencies, and both parties identified providing this level of support as beyond their scope and/or capacity given their time constraints. Interestingly, the debate of greater support versus greater autonomy was recently explored in the popular press, as the New York Times reported on the experiences of Canadian families participating in a new, intensive program, "adopting" Syrian refugee families for the first year after arrival. ${ }^{29}$ Further scientific study comparing outcomes for families with more intensive support versus families with the standard government support will yield interesting insight to this issue.

\section{Limitations}

This study is limited by its sample size and restriction to a single urban location. To create a more comprehensive understanding of the challenges in health care provision, focus groups with refugee patients and physicians, and more groups with case managers and clinical staff, would be beneficial. Quality improvement studies assessing the effects of suggested interventions (ie, increased care coordination outside the visits, prolonged visit time to allow for greater education, additional physician education) are essential as the next steps in the efforts to improve outcomes for this vulnerable population. Furthermore, studies investigating assets and strengths within existing communities and programs in regard to refugee health would be beneficial for overall goals of optimizing refugee care and support.

\section{CONCLUSIONS}

Refugee patients and all other participants in refugee health (eg, case managers, interpreters, physicians, and ancillary staff) work to navigate a complicated path to equitable health care for this vulnerable population. Continued efforts on strategies for increased time allocation, education, and support for all parties are needed as we seek to improve health outcomes for newly arrived refugee families.

\section{Patient-Friendly Recap}

- Cultural differences and complex logistics make providing health care to refugees, a patient population at high risk for significant preexisting medical problems, difficult.

- The authors conducted focus groups comprised of case managers, medical interpreters, and pharmacists to explore refugee care challenges.

- Participants reported language barriers, low education level and lack of trust, combined with a dearth of available resources, negatively impact clinic visits.

- Efforts to improve refugee health care should target increases in time allocation, education, and support for both patients and caregivers. 


\section{Author Contributions}

Study design: all authors. Data acquisition or analysis: all authors. Manuscript drafting: Kotovicz. Critical revision: Vo, Getzin.

\section{Conflicts of Interest}

None.

\section{References}

1. Shannon PJ, Vinson GA, Cook TL, Lennon E. Characteristics of successful and unsuccessful mental health referrals of refugees. Adm Policy Ment Health. 2016;43:555-68. CrossRef

2. Mirza M, Luna R, Mathews B, et al. Barriers to healthcare access among refugees with disabilities and chronic health conditions resettled in the US Midwest. J Immigr Minor Health. 2014;16:733-42. CrossRef

3. Joshi C, Russell G, Cheng IH, et al. A narrative synthesis of the impact of primary health care delivery models for refugees in resettlement countries on access, quality and coordination. Int J Equity Health. 2013;12:88. CrossRef

4. Kaplan I, Stow HD, Szwarc J. Responding to the challenges of providing mental health services to refugees: anAustralian case report. J Health Care Poor Underserved. 2016;27:1159-70. CrossRef

5. Asgary R, Segar N. Barriers to health care access among refugee asylum seekers. J Health Care Poor Underserved. 2011;22:506-22. CrossRef

6. Nies MA, Lim WY, Fanning K, Tavanier S. Importance of interprofessional healthcare for vulnerable refugee populations. J Immigr Minor Health. 2016;18:941-3. CrossRef

7. Bellamy K, Ostini R, Martini N, Kairuz T. Access to medication and pharmacy services for resettled refugees: a systematic review. Aust J Prim Health. 2015;21:273-8. CrossRef

8. Farley R, Askew D, Kay M. Caring for refugees in general practice: perspectives from the coalface. Aust J Prim Health. 2014;20:85-91. CrossRef

9. Jiwrajka M, Mahmoud A, Uppal M. A Rohingya refugee's journey in Australia and the barriers to accessing healthcare. BMJ Case Rep. Epub 2017 May 9. CrossRef

10. Morris MD, Popper ST, Rodwell TC, Brodine SK, Brouwer KC. Healthcare barriers of refugees post-resettlement. J Community Health. 2009;34:529-38. CrossRef

11. Morrison TB, Wieland ML, Cha SS, Rahman AS, Chaudhry R. Disparities in preventive health services among Somali immigrants and refugees. J Immigr Minor Health. 2012;14:968-74. $\underline{\text { CrossRef }}$

12. Shannon PJ, Vinson GA, Cook TL, Lennon E. Characteristics of successful and unsuccessful mental health referrals of refugees. Adm Policy Ment Health. 2016;43:555-68. CrossRef

13. Cheng IH, Drillich A, Schattner P. Refugee experiences of general practice in countries of resettlement: a literature review. Br J Gen Pract. 2015;65:e171-6. CrossRef
14. Terasaki G, Ahrenholz NC, Haider MZ. Care of adult refugees with chronic conditions. Med Clin North Am. 2015;99:1039-58. CrossRef

15. Njeru JW, Boehm DH, Jacobson DJ, et al. Diabetes outcome and process measures among patients who require language interpreter services in Minnesota primary care practices. J Community Health. 2017;42:819-25. CrossRef

16. Green M. Language barriers and health of Syrian refugees in Germany. Am J Public Health. 2017;107:486. CrossRef

17. Cheng IH, Vasi S, Wahidi S, Russell G. Rites of passage: improving refugee access to general practice services. Aust Fam Physician. 2015;44:503-7.

18. Davidson N, Skull S, Burgner D, et al. An issue of access: delivering equitable health care for newly arrived refugee children in Australia. J Paediatr Child Health. 2004:40:569-75. CrossRef

19. Elwell D, Junker S, Sillau S, Aagaard E. Refugees in Denver and their perceptions of their health and health care. J Health Care Poor Underserved. 2014;25:128-41. CrossRef

20. Getzin A, Bobot BL, Simpson D. Sustaining family physicians in urban underserved settings. Fam Med. 2016;48:809-13.

21. Onwuegbuzie AJ, Dickinson WB, Leech NL, Zoran AG. A qualitative framework for collecting and analyzing data in focus group research. Int J Qual Methods. 2009;8(3):1-21. CrossRef

22. Lingard L, Kennedy TJ. Qualitative Research in Medical Education. Edinburgh, U.K.: Association for the Study of Medical Education, 2007.

23. Patel K, Auton MF, Carter B, et al. Parallel-serial memoing: a novel approach to analyzing qualitative data. Qual Health Res. 2016;26:1745-52. CrossRef

24. Polcher K, Calloway S. Addressing the need for mental health screening of newly resettled refugees: a pilot project. J Prim Care Community Health. 2016;7:199-203. CrossRef

25. Posselt M, McDonald K, Procter N, de Crespigny C, Galletly C. Improving the provision of services to young people from refugee backgrounds with comorbid mental health and substance use problems: addressing the barriers. BMC Public Health. 2017;17(1):280. CrossRef

26. Kirmayer LJ, Narasiah L, Munoz M, et al. Common mental health problems in immigrants and refugees: general approach in primary care. CMAJ. 2011;183:E959-67. CrossRef

27. Jensen NK, Norredam M, Priebe S, Krasnik A. How do general practitioners experience providing care to refugees with mental health problems? A qualitative study from Denmark. BMC Fam Pract. 2013;14:17. CrossRef

28. Dubus N. Interpreters' subjective experiences of interpreting for refugees in person and via telephone in health and behavioural health settings in the United States. Health Soc Care Community. 2016;24:649-56. CrossRef

29. Kantor J, Einhorn C. Canadians adopted refugee families for a year. Then came 'Month 13.' New York Times. 2017 Mar 25. https://www.nytimes.com/2017/03/25/world/canada/ syrian-refugees.html. Accessed July 7, 2017.

(C) 2018 Aurora Health Care, Inc. 